\title{
Alumina Coatings on Fluorine-Doped Tin Oxide@Titanium Dioxide as Photoanode for
}

\section{Dye-Sensitized Solar Cells}

Lu Zhou ${ }^{a}$, Ye Feng Wang ${ }^{\text {b, }}$, Fu Ming Ren ${ }^{\mathrm{d}}$, Xiao Rui Cui ${ }^{\mathrm{a}}$, Jing Hui Zeng ${ }^{\mathrm{a}, \mathrm{c}, *}$

a School of Materials Science and Engineering, b School of Chemistry and Chemical Engineering, ${ }^{\mathrm{c}}$ Key Laboratory of Macromolecular Science of Shaanxi Province, Shaanxi Normal University, Xi'an, China, 710620, ${ }^{\mathrm{d}}$ Department of Municipal and Environment Engineering, Beijing Jiaotong University, Beijing, China, 100044.

Figures

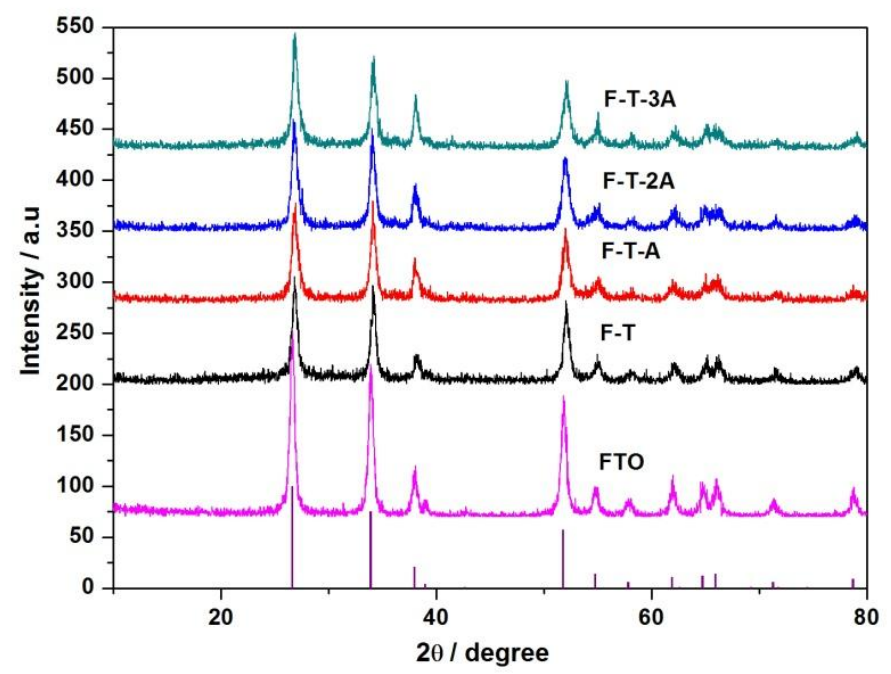

Figure 1. X-ray diffraction patterns of the FTO nanoparticles, F-T and F-T- $x$ A films.

\footnotetext{
*Corresponding author: J. H. Zeng, email: jhzeng@ ustc.edu
} 


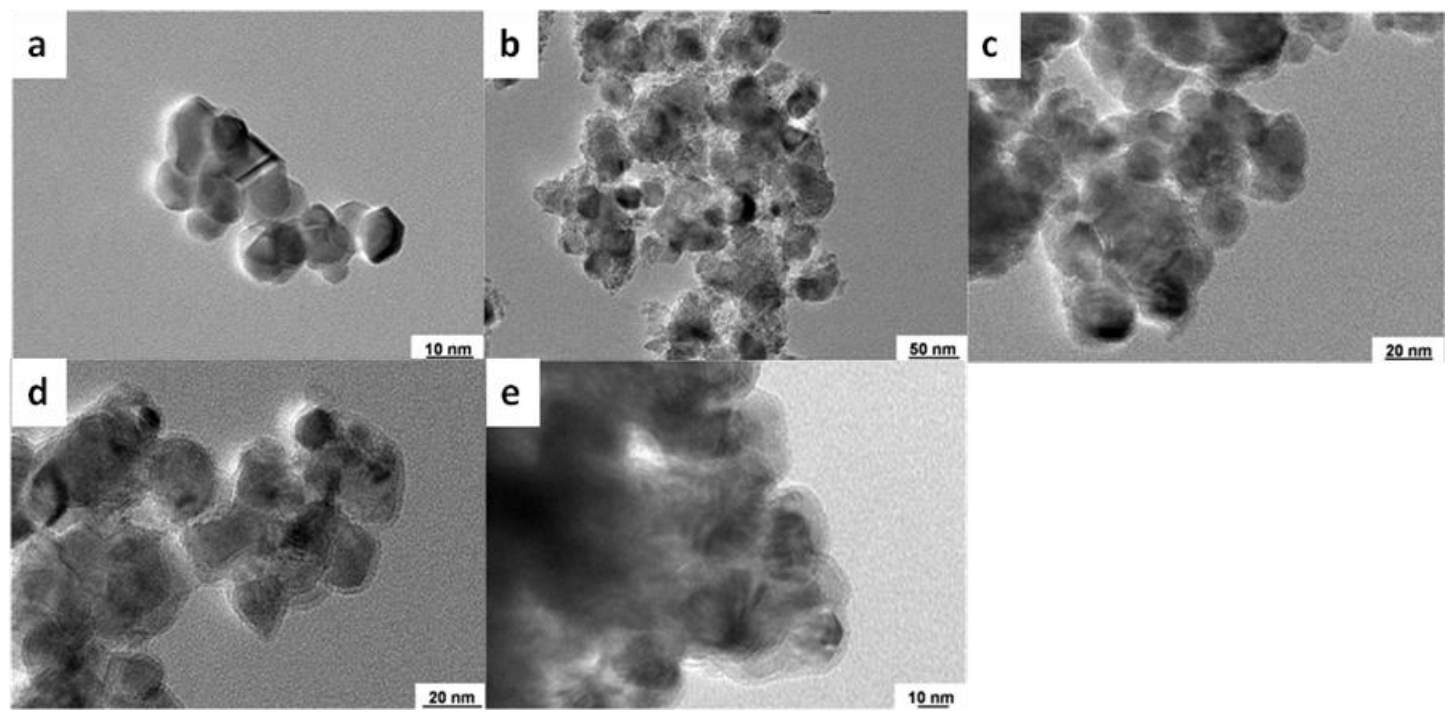

Figure 2. Typical TEM images of the synthesized FTO nanoparticles, F-T nanoparticles and F-T- $x$ A nanoparticles gained from corresponding films. (a) FTO nanoparticle with a diamiter of about $20 \mathrm{~nm}$. (b) F-T nanoparticles. (c) F-T-A nanoparticles. (d) F-T-2A nanoparticles. (e) F-T-3A nanoparticles. 

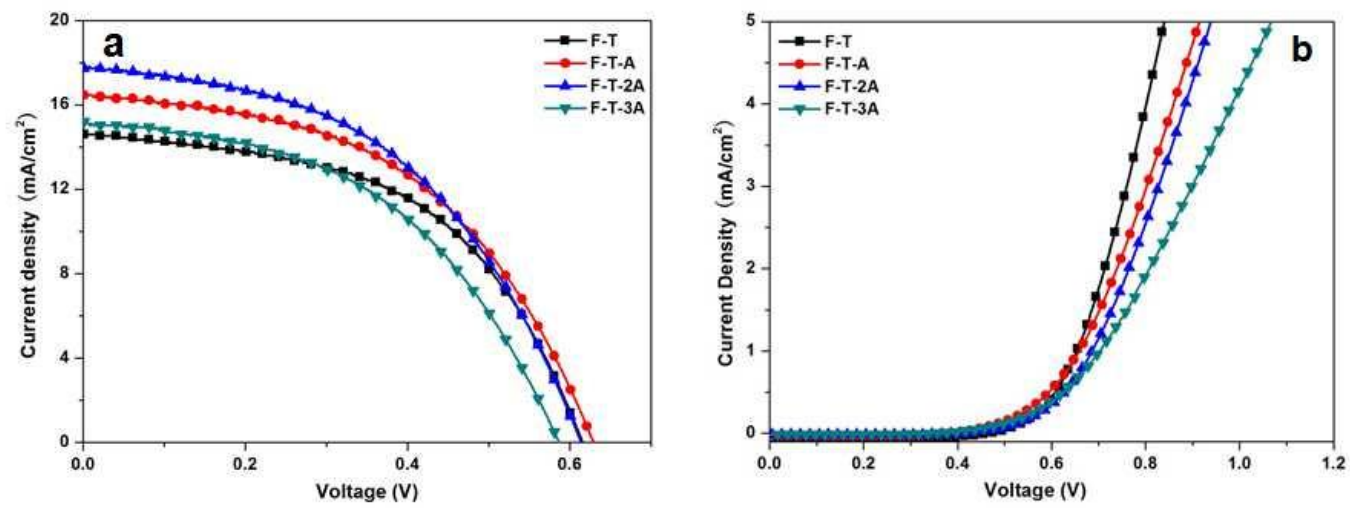

Figure 3. Typical $J-V$ curves of DSCs based on FTO NPs, F-T films and F-T- $x$ A films (a) under illumination of AM $1.5 \mathrm{G}$ and (b) under dark, The area of all devices is $0.36 \mathrm{~cm}^{2}$. 


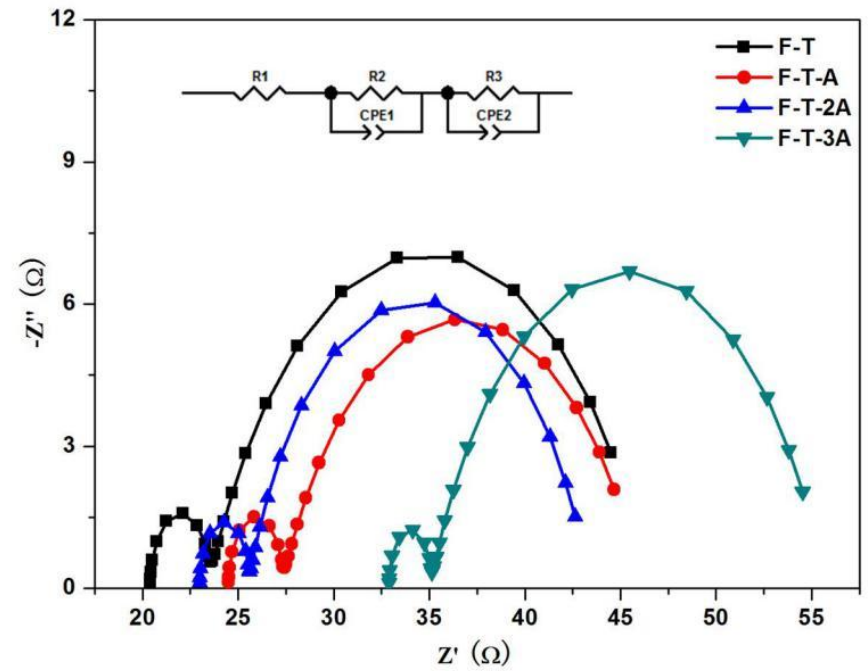

Figure 4. Nyquist plots of representative EIS datas at $800 \mathrm{mV}$ forward bias under illumination for F-T and F-T- $x$ A based DSCs. Inset: equivalent circuit corresponding to different interface in dye sensitized solar cells. 


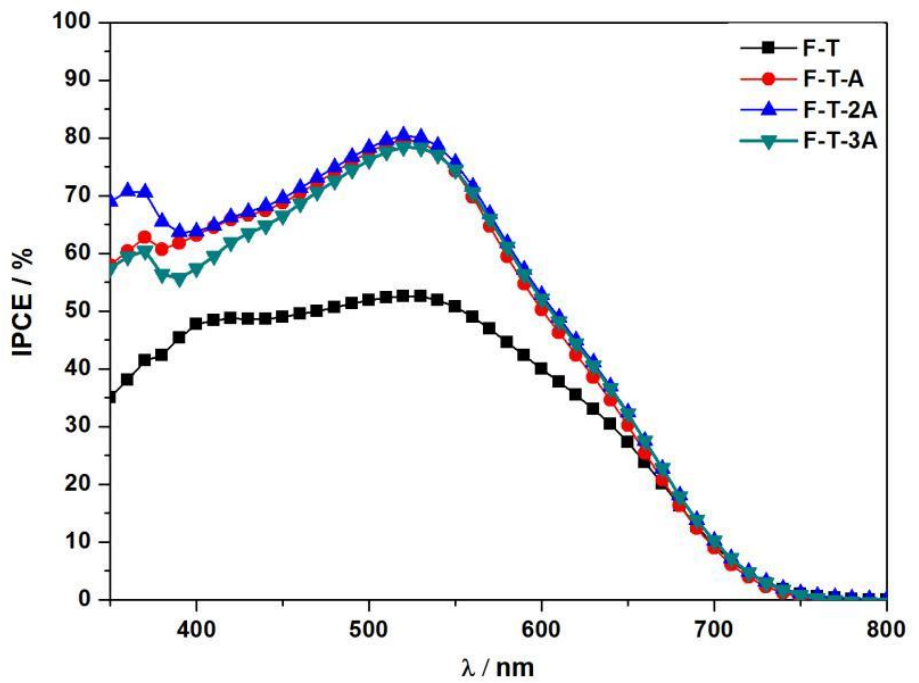

Figure 5. IPCE for the DSCs based on F-T and F-T- $x$ A. 


\section{Alumina Coatings on Fluorine-Doped Tin Oxide@Titanium Dioxide as Photoanode for Dye-Sensitized Solar Cells}

Lu Zhou ${ }^{\mathrm{a}}$, Ye Feng Wang ${ }^{\mathrm{b}, \mathrm{c}}$, Fu Ming Ren ${ }^{\mathrm{d}}$, Xiao Rui Cui ${ }^{\mathrm{a}}$, Jing Hui Zeng ${ }^{\mathrm{a}, \mathrm{c}, *}$

a School of Materials Science and Engineering, ${ }^{b}$ School of Chemistry and Chemical Engineering, ${ }^{\mathrm{c}}$ Key Laboratory of Macromolecular Science of Shaanxi Province, Shaanxi Normal University, Xi'an, China, 710620, ${ }^{\mathrm{d}}$ Department of Municipal and Environment Engineering, Beijing Jiaotong University, Beijing, China, 100044.

Tables

Table 1. Photovoltaic Parameters of DSCs for F-T and F-T- $x$ A with same thickness.

\begin{tabular}{cccccc}
\hline Electrodes & $\begin{array}{c}J_{\mathrm{sc}} \\
\left(\mathrm{mA} / \mathrm{cm}^{2}\right)\end{array}$ & $\begin{array}{c}V_{\mathrm{oc}} \\
(\mathrm{V})\end{array}$ & $\begin{array}{c}F F \\
(\%)\end{array}$ & $\begin{array}{c}\eta \\
(\%)\end{array}$ & $\begin{array}{c}\text { Absorbed dye } \\
\left(\times 10^{-8} \mathrm{~mol} / \mathrm{cm}^{2}\right)\end{array}$ \\
\hline F-T & 14.61 & 0.613 & 52 & 4.66 & 9.93 \\
F-T-A & 16.47 & 0.629 & 49 & 5.11 & 8.33 \\
F-T-2A & 17.73 & 0.614 & 48 & 5.24 & 8.44 \\
F-T-3A & 15.20 & 0.586 & 48 & 4.27 & 9.47 \\
\hline
\end{tabular}

*Corresponding author: J. H. Zeng, email: jhzeng@ustc.edu 
Alumina Coatings on Fluorine-Doped Tin Oxide@Titanium Dioxide as Photoanode for

Dye-Sensitized Solar Cells

4

Lu Zhou ${ }^{\mathrm{a}}$, Ye Feng Wang ${ }^{\mathrm{b}, \mathrm{c}}$, Fu Ming Ren ${ }^{\mathrm{d}}$, Xiao Rui Cui ${ }^{\mathrm{a}}$, Xin Yi Wang ${ }^{\mathrm{a}}$, Jing Hui Zeng ${ }^{\mathrm{a}, \mathrm{c}, *}$

a School of Materials Science and Engineering, ${ }^{b}$ School of Chemistry and Chemical

6 Engineering, ${ }^{\mathrm{c}}$ Key Laboratory of Macromolecular Science of Shaanxi Province, Shaanxi

7 Normal University, Xi'an, China, 710620, ${ }^{\mathrm{d}}$ Department of Municipal and Environment

8 Engineering, Beijing Jiaotong University, Beijing, China, 100044.

Abstract Titanium dioxide coated fluorine doped tin oxide film (F-T film) is synthesized and applied as photoanode in dye-sensitized solar cells (DSCs). Efforts to improve the photovoltaic performance are made by coating an $\mathrm{Al}_{2} \mathrm{O}_{3}$ barrier layer to serve as the charge recombination barrier. Due to the less electron recombination with oxidized dye or $\mathrm{I}_{3}{ }^{-}$after two times of $\mathrm{Al}_{2} \mathrm{O}_{3}$ coating combined with an efficient electron extraction of F-T film, F-T-2A DSCs exhibits a maximal efficiency of $5.24 \%$ improved by $12.4 \%$ for F-T DSCs without surface modification. However the cell performance fades due to decreased photoelectron injection from dye molecules into $\mathrm{TiO}_{2}$ conduction band when the barrier became thicker. The thickness of $\mathrm{Al}_{2} \mathrm{O}_{3}$ by deposition cycle is well controlled and studied. Electrochemical impedance spectra are applied to disclose the low electron transfer resistance of F-T-2A DSCs for the better cell performance.

Keywords Fluorine doped tin oxide@titanium dioxide film; alumina barrier layer; dyesensitized solar cell; electron recombination

\footnotetext{
*Corresponding author: J. H. Zeng, email: jhzeng@ustc.edu
} 


\section{Introduction}

Conventional dye-sensitized solar cells (DSCs) are typically fabricated with mesoporous nanocrystalline $\mathrm{TiO}_{2}$ films as photoanodes. Improvements in the photovoltaic performance have been limited because of slow electron transport and charge recombination in $\mathrm{TiO}_{2}$ films [1]. One way to solve this problem is to use $\mathrm{TiO}_{2}$ coated FTO nanoparticle film (F-T film) as photoanode in DSCs $[2,3]$. We have recently demonstrated a higher efficiency compared to that received from mere P25 photoanode with one tenth dye loading using titanium coated FTO nanoparticles as photoanodes [4]. Unlike simply providing a direct electron transport channel using one-dimensional (1D) nanowires/nanotubes in DSCs which would dramatically decrease the dye absorption and then lead to an uncompetitive efficiency [5] or utilizing semiconductor with higher electron mobility like $\mathrm{ZnO}$ which is unstable in acid or $\mathrm{SnO}_{2}$ having weak bonding with dye molecules [6], F-T film can shrink the transport distance of electron via FTO's conductivity, maintain a relative high dye loading level by $\mathrm{TiO}_{2}$ shell, and keep the stable nature of traditional photoanodes. It can also decouple the contradictory demand in bare $\mathrm{TiO}_{2}$ film between fast charge transport which desires heavy doping and less electron recombination which desires light doping [2], because the light-injected electrons from the $\mathrm{TiO}_{2}$-dye interface in F-T DSCs only need to traverse a ultra thin layer of $\mathrm{TiO}_{2}$ prior to being extracted by the highly conductive FTO core via a drift-assisted transport [7] instead of diffusive transport [8] in bare $\mathrm{TiO}_{2}$ DSCs (a slow mechanism with electron escape times of 1-10 ms for $\sim 10-\mu$ m-thick $\mathrm{TiO}_{2}$ films) [9]. At the same time, due to the difference of Fermi levels between FTO (approximately $-4.8 \mathrm{eV}$ vs $\mathrm{E}_{\mathrm{vac}}$ ) and $\mathrm{TiO}_{2}$ (approximately $-4.4 \mathrm{eV}$ vs $\mathrm{E}_{\mathrm{vac}}$ ) $[2,10]$, electrons flowing from $\mathrm{TiO}_{2}$ to FTO layer in F-T photoanode results in band bending $[11,12]$ of $\mathrm{TiO}_{2}$. Under illumination, the conduction band of $\mathrm{TiO}_{2}$ inclines to $\mathrm{FTO}$, and the electrons can favorably drift downhill from $\mathrm{TiO}_{2}$ to FTO $[13,14,15]$. Thus enhanced electron extraction in F-T DSCs with no harm on dye absorption can be observed.

In DSCs made from F-T films, there exist several interfacial electron-transfer dynamics 
$\mathrm{TiO}_{2} /$ dye/electrolyte interfaces where the adsorption of photosensitizer, and the injection, transport, and the recombination of photoelectrons occur [16]. Because of the configuration of dye molecules, there exist some vacancies without the absorption of dye molecules [17] on the surface of F-T film leading to the recombination of injected electrons with oxidized dye molecules or the electrolytic ions, and the limited efficiency for DSCs as a result. So modifying the $\mathrm{TiO}_{2} /$ dye/electrolyte interfaces to minimize the possible recombination pathways via various methods is a focused research topic to improve the photovoltaic performance and stability of the DSCs. One important approach is to coat the surface of F-T film with large band gap semiconductor thin layers at the aim of increasing the physical separation of injected electrons with the oxidized dyes or redox couples. Studies to date have demonstrated improvements in DSCs device performance for films fabricated from $\mathrm{TiO}_{2}$ films coated with barrier layers like $\mathrm{Nb}_{2} \mathrm{O}_{5}$ [18], $\mathrm{MgO}[19,20], \mathrm{Al}_{2} \mathrm{O}_{3}$ [21,22,23], $\mathrm{ZrO}_{2}[24,25], \mathrm{SiO}_{2}$ [26]. Among them, $\mathrm{Al}_{2} \mathrm{O}_{3}$ has a matching band structure with the valence band situated well below the $\mathrm{TiO}_{2}$ valence band, and the conduction band is several electron volts above (at more negative potential) both the $\mathrm{TiO}_{2}$ conduction band edge and dye excited state oxidation potential indicating $\mathrm{Al}_{2} \mathrm{O}_{3}$ would function as physical barrier layers for both electron injection and charge recombination reactions [21]. Generally, a thicker $\mathrm{Al}_{2} \mathrm{O}_{3}$ barrier layer may result in a slower charge recombination rate but may reduce the forward charge injection at the same time. Therefore, an optimal thickness of the barrier layer should be pursued for harvesting the best performance of F-T solar cells.

In this work, F-T film was used instead of $\mathrm{TiO}_{2}$ as the photoanode. Redox-inactive $\mathrm{Al}_{2} \mathrm{O}_{3}$ was examined as a blocking layer on F-T for elimination of electron shunting. Surface sol-gel process conducted under mild experimental conditions was further used to deposit a conformal ultrathin layer of $\mathrm{Al}_{2} \mathrm{O}_{3}$ on F-T photoanodes, with the aim to modulate interfacial electron transfer dynamics and thereby improve the performance of DSCs combined with enhanced electron extraction of F-T film, A power conversion efficiency of 5.24\% is obtained, 
84

study on F-T DSCs offers a strategy toward optimizing the energy conversion efficiency of solar cells based on integrated effects of F-T film's enhanced electron extraction and $\mathrm{Al}_{2} \mathrm{O}_{3}$ film's suppression of electrons recombination.

\section{Experimental}

\subsection{Fabrication of FTO nanoparticle film}

All chemicals used in this paper were analytical grade without further purification. The synthesis of FTO was based on a modified method according to the previous report [27]. $4.513 \mathrm{~g} \mathrm{SnCl}_{2} \cdot 2 \mathrm{H}_{2} \mathrm{O}$ and $0.3 \mathrm{ml} 40 \% \mathrm{HF}$ were dissolved in $200 \mathrm{~mL}$ deionized water. A solution of $8 \mathrm{~mL}$ acetylacetone in $30 \mathrm{~mL}$ methanol was slowly added to the above mixed solution for $1 \mathrm{~h}$ with rapid stirring. $2 \mathrm{~h}$ later, aqueous ammonia solution was dropped into the mixed solutions until the $\mathrm{PH}$ reached 9.5 to get gel formation. The resulting gel product was filtered and washed several times with deionized water till removal of the entire $\mathrm{Cl}^{-}$which could be checked by $0.1 \mathrm{M} \mathrm{AgNO}_{3}$ solution before being transferred to the oven for further drying at $50{ }^{\circ} \mathrm{C}$. Dried material was ground homogeneously with a given mass of PEG 10000 and deionized water at a ratio of m:m (PEG):m $\left(\mathrm{H}_{2} \mathrm{O}\right)=1: 1: 1$ in a ball grinding mill for $7 \mathrm{~h}$ and nanopowder of FTO were obtained by calcinating in furnace for $2 \mathrm{~h}$ at $600{ }^{\circ} \mathrm{C}$. After cooling down, a paste was achieved by grinding FTO nanopowder with PVDF and NMethylpyrrolidinone at a mass ratio of $\mathrm{m}$ (FTO): $\mathrm{m}$ (PVDF): $\mathrm{m}$ (N-Methylpyrrolidinone) $=$ 7:1:14. The FTO nanoparticulate film was prepared by doctor blading of a thin layer FTO nanoparticle paste on the FTO substrate and sintered at $450{ }^{\circ} \mathrm{C}$ for 30 minutes.

\subsection{Surface modification}

To coat a $\mathrm{TiO}_{2}$ shell, the FTO nanoparticulate electrodes were processed with $\mathrm{TiCl}_{4}$ treatment by immersing the $\mathrm{FTO}$ anodes in $45 \mathrm{mM} \mathrm{TiCl} 4$ aqueous solution in a sealed watch glass and kept at $80^{\circ} \mathrm{C}$ for 30 minutes, later rinsing with water and placing the electrodes in an oven at $50{ }^{\circ} \mathrm{C}$ until being completely dried. This process should be repeated twice according to our previous report [4]. To prepare co-surface treatment samples, after $\mathrm{TiO}_{2}$ coating, the electrodes should be hydroxylated by dropping $10 \mu 1$ deionized water untill they 
111 dried, then dipping the electrodes in a solution of suitable precursor as $0.05 \mathrm{M}$ solution of

112 aluminum isopropoxide in dry ethanol followed by rinsing with ethanol and sintering at

$113550{ }^{\circ} \mathrm{C}$ for $30 \mathrm{~min}$, The thickness of the barrier layer was controlled precisely by the

114 deposition cycle 1, 2 and 3 represented as F-T- $x \mathrm{~A}(x=1,2,3)$.

$115 \quad 2.3$ Solar cell fabrication

116 After surface treatment, the electrodes were sensitized overnight in $0.5 \mathrm{mM}\left(\mathrm{Bu}_{4} \mathrm{~N}\right)_{2^{-}}$ $117\left[\mathrm{Ru}\left(4,4-(\mathrm{COOH})-2,2^{\prime} \text {-bipyridine }\right)_{2}(\mathrm{NCS})_{2}\right](\mathrm{N} 719)$ in ethanol solution. A $50 \mu \mathrm{m}$ hot melt 118 sealing foil (Surlyn) was sandwiched between the electrode and a platinized FTO with two 119 open pores. The electrolyte, consisting of $0.3 \mathrm{M}$ DMPII, $0.5 \mathrm{M} \mathrm{LiI}, 0.05 \mathrm{M} \mathrm{I}_{2}$, and $0.4 \mathrm{M} 4-$ 120 TBP in methoxypropionitrile, was injected from the side of the electrodes.

\section{$121 \quad 2.4$ Materials characterization}

$\mathrm{X}$-ray diffraction (XRD) measurements were carried out using a D/Max-3c X-ray diffractometer with $\mathrm{Cu} \mathrm{K} \alpha(\lambda=0.154 \mathrm{~nm})$, scanning from $5^{\circ}$ to $80^{\circ}$ and using an operation voltage and current of $40 \mathrm{kV}$ and $30 \mathrm{~mA}$, respectively. Scanning electron microscopy (SEM) images and EDS date were taken on a JEOL JSM-6700 FSEM. Transmission electron microscope (TEM) images were collected by using a JEM-2100 microscope. Specimens for TEM observation were prepared by dispersing the material powder into alcohol by an ultrasonic treatment.

\subsection{Electrochemical measurements}

A $350 \mathrm{~W}$ xenon light source (ShangHai) was used to provide the $J$ - $V$ curves under an incident irradiance of AM 1.5G $\left(100 \mathrm{~mW} / \mathrm{cm}^{2}\right)$ for solar cells. EIS analyses were conducted with the bias voltage set at an applied voltage of $0.8 \mathrm{~V}$ and the frequency set from $0.1 \mathrm{~Hz}$ to $100 \mathrm{kHz}$ with oscillation amplitude of $5 \mathrm{mV}$ at $\mathrm{AM} 1.5 \mathrm{G}\left(100 \mathrm{~mW} / \mathrm{cm}^{2}\right)$. The IPCE was measured as a function of wavelength from 300 to $800 \mathrm{~nm}$ by using CROWNTECH Q-test station 500TI. The N719 dye absorbed on the $\mathrm{TiO}_{2}$ films was obtained by using the UV-VISNIR spectrophotometer (TU-1901, Beijing). The specific operation is: the dye was desorbed 
138 the UV-vis spectrophotometer was employed to measure the absorbance of the desorbed-dye

139 solution at $500 \mathrm{~nm}$. According to the Lambert-Beer's law, the concentration of desorbed-dye

140 solution was achieved by measuring the absorbance of a dye solution at known concentration.

\section{Results and discussion}

The XRD patterns of FTO, F-T and F-T- $x$ A are shown in Fig. 1. The diffraction patterns of FTO, F-T and F-T-xA are well matched with cassiterite $\mathrm{SnO}_{2}$. The major peaks centered at $2 \theta$ of $26.6^{\circ}, 33.8^{\circ}, 37.9^{\circ}, 51.8^{\circ}$ and $65.9^{\circ}$ can be indexed to the (110), (101), (200), (211), and (301) facets of tetragonal cassiterite (JCPDS 41-1445). However the peaks associated with dopant $\mathrm{F}, \mathrm{TiO}_{2}$ and $\mathrm{Al}_{2} \mathrm{O}_{3}$ can't be directly identified by XRD.

The presence of $\mathrm{F}$ doping, $\mathrm{TiO}_{2}$ and $\mathrm{Al}_{2} \mathrm{O}_{3}$ was instead verified by EDS (Fig. S1). The atomic ratio of $\mathrm{F} / \mathrm{Sn}$ is calculated to be about 1:7. After $\mathrm{TiCl}_{4}$ treatment, the amount of $\mathrm{Ti}$ atoms account for $12.02 \%$. For one, two and three cycles of $\mathrm{Al}_{2} \mathrm{O}_{3}$ coating, the ratio of $\mathrm{Al}$ atoms increases from $1.41 \%$ to $5.40 \%$ immediately, suggesting a growing thickness of the $\mathrm{Al}_{2} \mathrm{O}_{3}$ layer along with the $\mathrm{Al}_{2} \mathrm{O}_{3}$ coating cycles.

\section{(Fig. 1)}

The morphologies, particle sizes and structures of FTO, F-T and F-T- $x$ A are characterized by the TEM. Fig. $2 \mathrm{a}$ is the image of the portion of the connected FTO nanoparticles. The average diameter of the FTO nanocrystalline is about $20 \mathrm{~nm}$ with irregular morphologies. Fig. 2b, c, d and e show the results from TEM investigation of the F-T, F-T-A, F-T-2A and F-T-3A. The core-shell structure can be clearly observed in TEM images. After $\mathrm{TiCl}_{4}$ treatment, a shell of $\mathrm{TiO}_{2}$ composed of nano-sized particles covers on the surface of FTO core particles which increases the active layer and leads to enhanced dye loading and light absorption [28]. Meanwhile a drift-assisted transport of photoinduced electrons formed at the $\mathrm{FTO} / \mathrm{TiO}_{2}$ interface to get an enhanced electron extraction [7]. To retard electron shunting, $\mathrm{Al}_{2} \mathrm{O}_{3}$ is deposited conformally on the surface of F-T film with thickness of about $1.5 \mathrm{~nm}$ after one time of sol-gel treatment, $2 \mathrm{~nm}$ for two times and $2.5 \mathrm{~nm}$ for three times. 
The photovoltaic performance of DSCs based on F-T and F-T- $x$ A with a film thickness

166 of $8 \mu \mathrm{m}$ (Fig. S2) were characterized under the simulated AM 1.5G illumination (100

$167 \mathrm{~mW} / \mathrm{cm}^{2}$ ). Typical $J-V$ curves of these DSCs are shown in Fig. 3a. The photovoltaic 168 parameters from the $J-V$ measurements are summarized in Tab. 1, including open circuit 169 voltage $\left(V_{\mathrm{oc}}\right)$, short-circuit current $\left(J_{\mathrm{sc}}\right)$, energy conversion coefficient $(\eta)$, fill factor $(F F)$ and 170 the amount of absorbed dye. With similar amount of absorbed dye for different photoanodes 171 (Fig. S3), the measured photocurrent of F-T DSCs is $14.61 \mathrm{~mA} / \mathrm{cm}^{2}$ and a conversion 172 efficiency of $4.66 \%$ is obtained. One time of $\mathrm{Al}_{2} \mathrm{O}_{3}$ coating causes the photocurrent and 173 conversion efficiency to be improved to $16.47 \mathrm{~mA} / \mathrm{cm}^{2}$ and $5.11 \%$, because of the less 174 recombination and small influence of the electron injection. After two times of $\mathrm{Al}_{2} \mathrm{O}_{3}$ coating, 175 the conversion efficiency reaches $5.24 \%$ which is improved by $12.4 \%$ compared to F-T DSCs 176 with a much higher photocurrent $17.73 \mathrm{~mA} / \mathrm{cm}^{2}$. In above two situations, "kinetic 177 redundancy" occurs in which the desirable charge-transfer step is much faster than the 178 competing undesirable step, such as in the case of electron injection into $\mathrm{TiO}_{2}$ conduction 179 band, which occurs at a much faster rate than the competing undesirable decay of the excited 180 electron recombination [29]. While three times later, both values decrease due to the stronger 181 interference with electron injection than with electron recombination caused by the thick $182 \mathrm{Al}_{2} \mathrm{O}_{3}$ layer. The lower $F F$ found in our F-T- $x$ A DSCs than F-T DSCs corresponds to the 183 uneven thickness of $\mathrm{Al}_{2} \mathrm{O}_{3}$ layer. The result has shown that two times of $\mathrm{Al}_{2} \mathrm{O}_{3}$ coating on F-T 184 film makes the electron recombination and injection reach a perfect balance which leads to 185 the highest conversion efficiency 5.24\%.

186 Previous investigations on the $\mathrm{Al}_{2} \mathrm{O}_{3}$ barrier layer were only on $\mathrm{TiO}_{2}$ nanocrystalline 187 electrodes or FTO electrodes. For instance, Palomares et al. showed a 2-2.5 nm $\mathrm{Al}_{2} \mathrm{O}_{3}$ barrier 188 layer coated on $\mathrm{TiO}_{2}$ film resulted in a $\sim 4$ fold retardation of the electron recombination with 189 dye cations, and an efficiency of 5\% was reached [30]. Another study by Liu et al. prepared a 190 thin $\mathrm{Al}_{2} \mathrm{O}_{3}$-sheathed 3-dimentional (3-D) fluorinated tin oxide (FTO) as photoanodes of DSCs, 191 at the aid of drift transport at the $\mathrm{FTO} / \mathrm{Al}_{2} \mathrm{O}_{3}$ interfaces, an efficiency of $1.536 \%$ was obtained 192 [7]. In addition, Gao et al. received improved photovoltaic performance made by using $\mathrm{Al}_{2} \mathrm{O}_{3}$ 
193 barrier layer coating on $\mathrm{TiO}_{2}$ nanotubes in conjunction with $\mathrm{TiCl}_{4}$ surface modification [31].

194 We have demonstrated $\mathrm{FTO} @ \mathrm{TiO}_{2}$ anode for DSCs with high efficiency at low dye loading 195 levels [4]. Coating of $\mathrm{Al}_{2} \mathrm{O}_{3}$ barrier layer on F-T films is conducted to further increase the 196 PCE by retarding the recombination processes. An efficiency of $5.24 \%$ is obtained.

197

198

199

200

201

The retardation of the electron recombination is reflected in the dark current characterizations. $J-V$ curves of F-T to F-T- $x$ A DSCs were traced in the dark (Fig. 3b). The thicker $\mathrm{Al}_{2} \mathrm{O}_{3}$ layer leads to a more efficient barrier layer for recombination and a higher recombination resistance [32]. So an enhanced suppression of the dark current with increasing barrier thickness of $\mathrm{Al}_{2} \mathrm{O}_{3}$ layer is received. In the figure, we can clearly indicate that cells with F-T-3A show the lowest dark current. The dark current increases from F-T-2A to F-T-A, then to uncoated F-T cells. The consequence of dark current density can well explain $J_{\text {sc }}$ under AM 1.5G illumination for cells with F-T, F-T-A, and F-T-2A due to the retardation of electron recombination. However, $J_{\mathrm{sc}}$ of F-T-3A is the lowest among the samples except for its lowest dark current density. The situation may be ascribed to the coating $\mathrm{Al}_{2} \mathrm{O}_{3}$ film above the optimal thickness, which hampers electron injection although it also retards electron recombination [21].

(Tab. 1)

\section{(Fig. 4)}

To uncover the competition between electron recombination and injection at the interfaces of different photoanodes, the EIS of F-T and F-T- $x$ A under illumination are shown in Fig. 4 at an applied bias of $0.8 \mathrm{~V}$ and a frequency range from $0.1 \mathrm{~Hz}$ to $1 \mathrm{MHz}$, with $\mathrm{AC}$ amplitude of $5 \mathrm{mV}$. Since DSCs can be viewed as an equivalent circuit combining a series resistor with some parallel connected resistor and capacitor [33] as illustrated in the inset of Fig. 4. The equivalent circuit can be simplified to a connection of a shunt resistor $R_{\mathrm{s}}$, to two 
219 sets of parallel connected resistors and capacitors, which is denoted as $R_{1}, \mathrm{CPE}_{1}$ and $R_{2}, \mathrm{CPE}_{2}$,

220 respectively [34]. $R_{\mathrm{S}}$ represents the series resistance reflecting the resistance of FTO substrate,

221 while $R_{1}$ and $R_{2}$ represent charge transport resistance at the counter electrode (first semicircle

in Nyquist plot) and charge transfer resistance at the photo working electrode/electrolyte

(second semicircle in Nyquist plot), respectively. Due to the lagging of current versus alternating voltage when it is applied on a capacitor, two semicircles can be well seen in a 
4. Conclusion F-T based electrodes were modified with an $\mathrm{Al}_{2} \mathrm{O}_{3}$ barrier layer for enhanced photovoltaic performance. The $\mathrm{Al}_{2} \mathrm{O}_{3}$ barrier layer suppresses the recombination between the injected electron and electrolyte or dye cations, but it suffers from the drawback of inhibiting photoelectron injections from the dye molecules to the F-T electrodes. This problem can be controlled by adjusting the thickness of $\mathrm{Al}_{2} \mathrm{O}_{3}$ barrier layer. In our experiments, F-T-2A presents superior properties with an accumulated recombination suppression effect and enhanced electron extraction deduced from EIS. The performance of the solar cells was improved significantly when compared with F-T DSCs. A high power conversion efficiency of $5.24 \%$ is finally obtained. This work identified that surface treatment is extremely important to optimize the DSC efficiency.

Acknowledgments This work was supported by the Natural Science Foundation of China (No. 21071093), the Fundamental Research Funds for the Central Universities (Grant No. GK201402017) from the Department of Education (DoE), and the outstanding doctoral dissertation project of Shaanxi Normal University (Grant No. 529 S2012YB03).

\section{References}

[1] Ramasamy, E.; Lee, J. W. Ordered Mesoporous $\mathrm{SnO}_{2}$-Based Photoanodes for HighPerformance Dye-Sensitized Solar Cell. J. Phys. Chem. C. 2010, 114, 22032-22037.

[2] Yang, Z. Z.; Gao, S. M.; Li, T.; Liu, F. Q.; Ren, Y.; Xu, T. Enhanced Electron Extraction from Template-Free 3D Nanoparticulate Transparent Conducting Oxide (TCO) Electrodes for DyeSensitized Solar Cells. ACS Appl. Mater. Interfaces 2012, 4, 4419-4427.

[3] Yang, Z.; Gao, S.; Li, W.; Vlasko-Vlasov, V.; Welp, U.; K. W. Wai; Xu, T. Three-Dimensional Photonic Crystal Fluorinated Tin Oxide (FTO) Electrodes: Synthesis, Optic and Electrical Properties. ACS Appl. Mater. Interfaces 2011, 3, 1101-1108.

[4] Cui, X. R.; Wang, Y. F.; Li, Z.; Zhou, L.; Gao, F.; Zeng, J. H. Micrometer-Sized Fluorine Doped Tin Oxide as Fast Electron Collector for Enhanced Dye-Sensitized Solar Cells. ACS Appl. Mater. Interfaces 2014, 6, 16593-16600.

[5] Liu, B.; Aydil, E. S. Growth of Oriented Single-Crystalline Rutile $\mathrm{TiO}_{2}$ Nanorods on Transparent Conducting Substrates for Dye-Sensitized Solar Cells. J. Am. Chem. Soc. 2009, 
$131,3985-3990$.

278

279

280

281

282

283

284

285

286

287

288

289

290

291

292

293

294

295

296

297

298

299

300

301

302

303

304

305

306

307

308

309

310

311

312

313

314

[6] Kay, A.; Grätzel, M. Dye-Sensitized Core-Shell Nanocrystals: Improved Efficiency of Mesoporous Tin Oxide Electrodes Coated with a Thin Layer of an Insulating Oxide. Chem. Mater. 2002, 14, 2930-2935.

[7] Liu, F. Q.; Zhu, K.; Li, T.; Xu, T. Drift Transport in $\mathrm{Al}_{2} \mathrm{O}_{3}$-Sheathed 3D Transparent Conducting Oxide Photoanodes Observed in Liquid Electrolyte-Based Dye-Sensitized Solar Cells. J. Phys. Chem. C 2014, 118, 9951-9957.

[8] Kopidakis, N.; Schiff, E. A.; Park, N. G.; van de Lagemaat, J.; Frank, A. J. Ambipolar Diffusion of Photocarriers in Electrolyte-Filled, Nanoporous $\mathrm{TiO}_{2}$. J. Phys. Chem. B 2000, 104, 3930-3936.

[9] Kopidakis, N.; Benkstein, K. D.; van de Lagemaat, J.; Frank, A. J. Transport-Limited Recombination of Photocarriers in Dye-Sensitized Nanocrystalline $\mathrm{TiO}_{2}$ Solar Cells. J. Phys. Chem. B 2003, 107, 11307-11315.

[10] Turrion M.; bisquert J.; Salvador P. Flat band potential of F: $\mathrm{SnO}_{2}$ in a $\mathrm{TiO}_{2}$ dye-sensitized solar cell: an interference reflection study. J. Phys. Chem. B 2003, 107, 9397-9403.

[11] Jacobsen, V.; Dür, M.; Wendling, B.; Yasuda, A.; Nelles, G.; Knoll, W.; Kreiter, M. Electronic properties of nanoporous $\mathrm{TiO}_{2}$ films investigated in real space by means of scanning tunnelling spectroscopy. Appl. Surf. Sci. 2006, 252, 3903-3911.

[12] Breeze, A. J.; Schlesinger, Z.; Carter, S. A.; Brock, P. J. Charge transport in $\mathrm{TiO}_{2} / \mathrm{MEH}-\mathrm{PPV}$ polymer photovoltaics. Phys. Rev. B 2001, 64, 125205/1-125205/9.

[13] Rühle, S.; Dittrich, T. Investigation of the Electric Field in $\mathrm{TiO}_{2} /$ FTO Junctions Used in DyeSensitized Solar Cells by Photocurrent Transients. J. Phys. Chem. B 2005, 109, 9522-9526.

[14] Rühle, S.; Cahen, D. Electron Tunneling at the $\mathrm{TiO}_{2} /$ Substrate Interface Can Determine DyeSensitized Solar Cell Performance. J. Phys. Chem. B 2004, 108, 17946-17951.

[15] Schlichthörl, G.; Park, N. G.; Frank, A. J. Evaluation of the Charge-Collection Efficiency of Dye-Sensitized Nanocrystalline $\mathrm{TiO}_{2}$ Solar Cells. J. Phys. Chem. B 1999, 103, 782-791.

[16] Nepal, J.; Mottaghian, S. S.; Biesecker, M.; Baroughi, F. M. Modeling of trap assisted interfacial charge transfer in dye sensitized solar cells. Appl. Phys. Lett. 2013, 102, 203503/1203503/4.

[17] Kumara G. R. R. A.; Tennakone K.; Perera V. P. S.; Konno A.; Kaneko S.; Okuya M. Suppression of recombinations in a dye-sensitized photo electrochemical cell made from a film of tin IV oxide crystallites coated with a thin layer of aluminium oxide. J. Phys. D: Appl. Phys. 2001, 34. 868-873.

[18] Zaban, A.; Chen, S. G.; Chappel, S.; Gregg, B. A. Bilayer Nanoporous Electrodes for Dye Sensitized Solar Cells. Chem. Commun. 2000, 22, 2231-2232.

[19] Green, A. N. M.; Palomares, E.; Haque, S. A.; Kroon, J. M.; Durrant, J. R. Charge Transport versus Recombination in Dye Sensitized Solar Cells Employing Nanocrystalline $\mathrm{TiO}_{2}$ and $\mathrm{SnO}_{2}$ Films. J. Phys. Chem. B 2005, 109, 12525-12533. 
[20] Jung, H. S.; Lee, J.; Nastasi, M.; Lee, S.; Kim, J.; Park, J.; Hong, K. S.; Shin, H. Preparation of Nanoporous MgO-Coated $\mathrm{TiO}_{2}$ Nanoparticles and Their Application to the Electrode of Dye-Sensitized Solar Cells. Langmuir 2005, 21, 10332-10335.

[21] Palomares, E.; Clifford, J. N.; Haque, S. A.; Lutz, T.; Durrant, J. R. Control of Charge Recombination Dynamics in Dye Sensitized Solar Cells by the Use of Conformally Deposited Metal Oxide Blocking Layers. J. Am. Chem. Soc. 2003, 125, 475-482.

[22] Prasittichai, C.; Hupp, J. T. Surface Modification of $\mathrm{SnO}_{2}$ Photoelectrodes in Dye-Sensitized Solar Cells: Significant Improvements in Photovoltage via $\mathrm{Al}_{2} \mathrm{O}_{3}$ Atomic Layer Deposition. $J$. Phys. Chem. Lett. 2010, 1, 1611-1615.

[23] Tien, T.; Pan, F.; Wang, L.; Lee, C.; Tung, Y.; Tsai, S.; Lin, C.; Tsai, F.; Chen, S. Interfacial energy levels and related properties of atomic-layer-deposited $\mathrm{Al}_{2} \mathrm{O}_{3}$ films on nanoporous $\mathrm{TiO}_{2}$ electrodes of dye-sensitized solar cells. Nanotechnol. 2009, 20, 305201/1-305201/8.

[24]Li, T. C.; Goes, M. S.; Fabregat-Santiago, F.; Bisquert, J.; Bueno, P. R.; Prasittichai, C.; Hupp, J. T.; Marks, T. J. Surface Passivation of Nanoporous $\mathrm{TiO}_{2}$ via Atomic Layer Deposition of $\mathrm{ZrO}_{2}$ for Solid-State Dye-Sensitized Solar Cell Applications. J. Phys. Chem. C 2009, 113, 18385-18390.

[25] Menzies, D. B.; Dai, Q.; Bourgeois, L.; Caruso, R. A.; Cheng, Y.; Simon, G. P.; Spiccia, L. Modification of mesoporous $\mathrm{TiO}_{2}$ electrodes by surface treatment with titanium(IV), indium(III) and zirconium(IV) oxide precursors: preparation, characterization and photovoltaic performance in dye-sensitized nanocrystalline solar cells. Nanotechnol. 2007, 18, 125608/1-125608/11.

[26] Kay, A.; Gratzel, M. Dye-Sensitized Core-Shell Nanocrystals: Improved Efficiency of Mesoporous Tin Oxide Electrodes Coated with a Thin Layer of an Insulating Oxide. Chem. Mater. 2002, 14, 2930-2935.

[27] Senthilkumar, V.; Vickraman, P.; Ravikumar, R. Synthesis of Fluorine-Doped Tin Oxide Nanoparticles by Sol-Gel Technique and Their Characterization. J. Sol-Gel Sci. Technol. 2010, 53, 316-321.

[28] P. M. Sommeling; B. C. O'Regan; R. R. Haswell; H. J. P. Smit; N. J. Bakker; J. J. T. Smits; J. M. Kroon; J. A. M. van Oosmalen. Influence of a $\mathrm{TiCl}_{4}$ Post-Treatment on Nanocrystalline $\mathrm{TiO}_{2}$ Films in Dye-Sensitized Solar Cells. J. Phys. Chem. B 2006, 110, 19191-19197.

[29] Haque, S. A.; Palomares, E.; Cho, B. M.; Green, A. N. M.; Hirata, N.; Klug, D. R.; Durrant, J. R. Charge Separation Versus Recombination in Dye-Sensitized Nanocrystalline Solar Cells: The Minimization of Kinetic Redundancy. J. Am. Chem. Soc. 2005, 127, 3456-3462.

[30] Palomares, E.; Clifford, J. N.; Haque, S. A.; Lutz, T.; Durrant, J. R. Slow charge recombination in dye-sensitised solar cells (DSSC) using $\mathrm{Al}_{2} \mathrm{O}_{3}$ coated nanoporous $\mathrm{TiO}_{2}$ films. Chem. Commun. 2002, 14, 1464-1465.

[31] Gao, X. F.; Guan, D. S.; Huo, J. W.; Chen, J. H.; Yuan, C. Free standing $\mathrm{TiO}_{2}$ nanotube array electrodes with an ultra-thin $\mathrm{Al}_{2} \mathrm{O}_{3}$ barrier layer and TiCl4 surface modification for highly 
efficient dye sensitized solar cells. Nanoscale 2013, 5, 10438-10446.

[32] Roelofs, K. E.; Brennan, T. P.; Dominguez, J. C.; Bailie, C. D.; Margulis, G. Y.; Hoke, E. T.; McGehee, M. D.; Bent, S. F. Effect of $\mathrm{Al}_{2} \mathrm{O}_{3}$ Recombination Barrier Layers Deposited by Atomic Layer Deposition in Solid-State CdS Quantum Dot-Sensitized Solar Cells. J. Phys. Chem. C 2013, 117, 5584-5592.

[33] Wang, Y. F.; Zeng, J. H.; Li, Y. Silver/Titania Nanocable as Fast Electron Transport Channel for Dye-Sensitized Solar Cells, Electrochim. Acta 2013, 87, 256-260.

[34] Jang, Y. H.; Xin, X. K.; Byun, M.; Jang, Y. J.; Lin, Z. Q.; Kim, D. H. An Unconventional Route to High-Efficiency Dye-Sensitized Solar Cells via Embedding Graphitic Thin Films into $\mathrm{TiO}_{2}$ Nanoparticle Photoanode. Nano Lett. 2012, 12, 479-485. 